
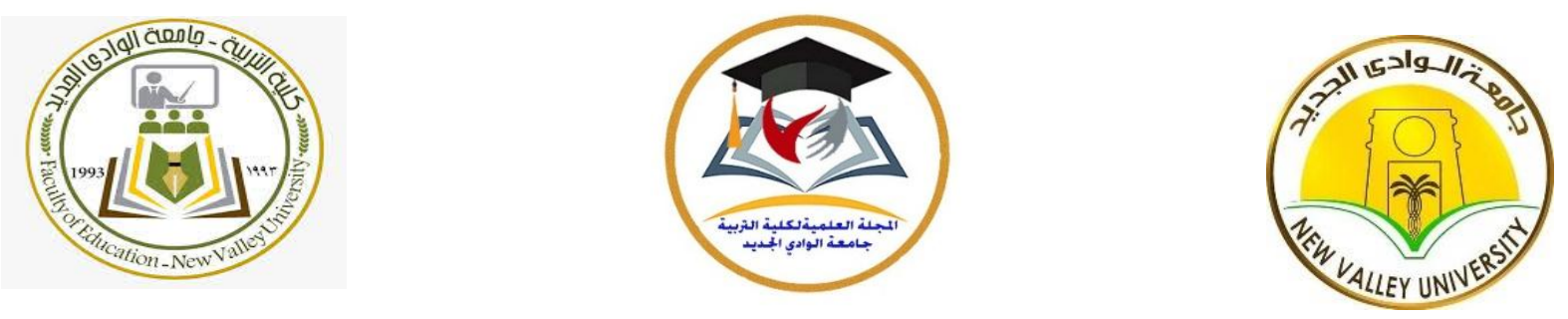

علاقة المساندة الاجتماعية بالخجل لاى المراهقات بالمرحلة الإعدادية

\title{
إعداد الباحثة
}

هالة عبد اللطيف حسين معوض

إثراف

د / سمية مختار وافي

مدرس الصحة النفسية بكلية التربية

جامعة الوادي الجديد
أ.د.م / محمود إبراهيم عبد العزيز

أستاذ الصحة النفسية المساعد بكلية التربية

جامعة الوادي الجديد 
هدفت الدراسة إلى تحديد العلاقة الارتباطية بين المساندة الاجتماعية و الخجل لدى المراهقات ،

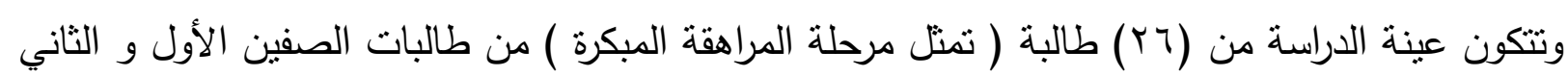

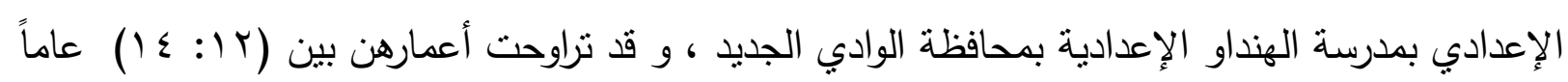

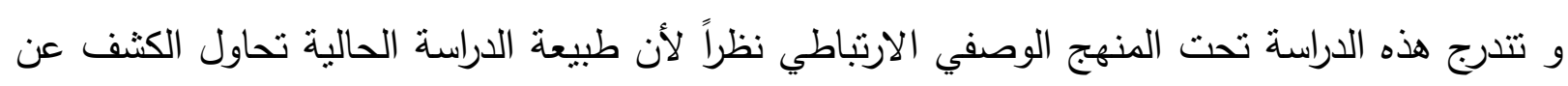

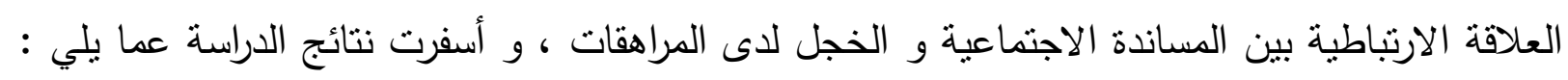
توجد علاقة ارتباطية سالبة دالة إحصائياً بين المساندة الاجتماعية و الخجل لدى المراهقات ـ

\section{Study Summary :}

The study aimed to determine the correlation between social support and shyness among adolescents girls. The study sample consists of (26) students (representing the early stage of adolescence ) consists of a group of students of the first and the second preparatory grades in Al Hindaw preparatory school in New Valley . Their ages ranges from $(12: 14)$ years . This study used relational descriptive approach to reveal the correlation between social support and shyness among adolescent girls the study revealed results as follows : there is a negative correlation between social support and shyness among adolescents girls . 
تعد مرحلة المراهقة من أخطر و أهم المراحل التي تمر بها الفتاة ، حيث تمر من خلالها بعدة تغيرات هامة سواء من الناحية النفسية أو الجسمية أو العقلية مما يؤدي إلى صراعات داخلية و مشكلات نفسية منها الخجل الذي يعيق الفتاة المراهقة من التكيف مع الييئة المحيطة بها و يؤثر على التفاعل الاجتماعي مع الآخرين ، و يثير W. Ray Crozier (2009) إلى إن الخجولين يشعرون بكثير من القلق في المواقف

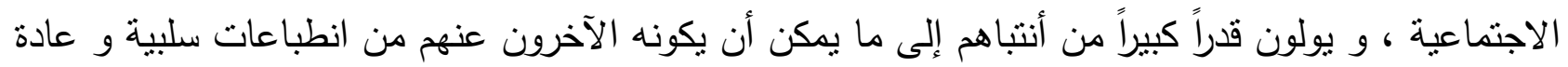

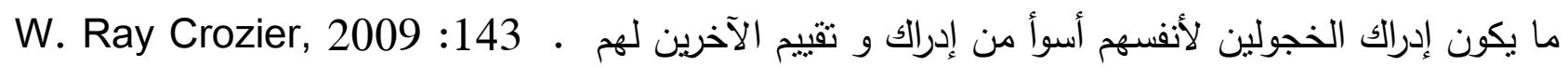

كما أن المراهق لا يسنطيع تحقيق تكيفه في جميع مجالات الحياة المختلفة و خاصة في المجال الدراسي ، و لهذا يواجه صعوبات كثيرة في علاقته بالآخرين ، وهذا ما يعيقه في حياته اليومية و يمنعه من الاتصال و التفاعل داخل المجتمع و بصفة خاصة داخل المدرسة فيكون المراهق المتمدرس معزولاً و مغترباً عن أقرانه ، مما يجعل أفكاره تتمحور حول ذاته فتكون نظرته إليها سلبية منتائمة ، و هذا ما يساهم في تدني

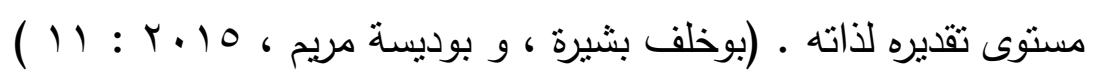

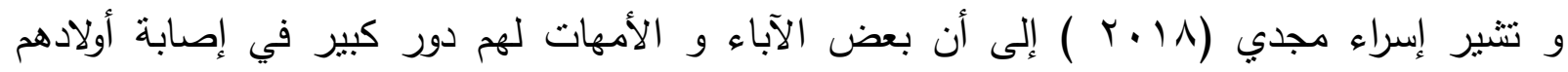
باضطرابات في السلوك منها الخجل ، و لايدرون بأنهم ساهموا في زرع هذا السلوك في نفوس أبنائهر . فالمراهق الذي يتعرض لانتقادات من قبل الكبار ينثأ ضعيف الثقة في النفس ، و يسيطر عليه الخوف و

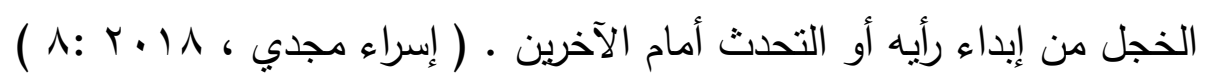
و نظراً لسلبيات الخجل العديدة فالمراهقة أو المراهق الخجول يحتاج إلى المساندة الاجتماعية و الدعم من

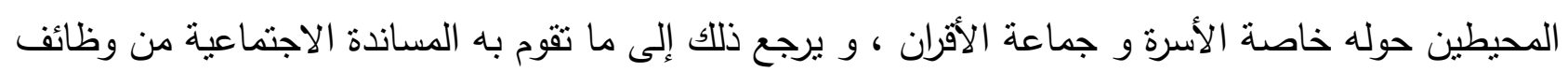

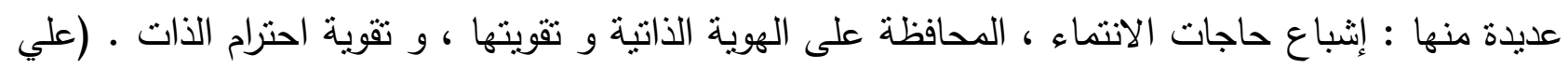

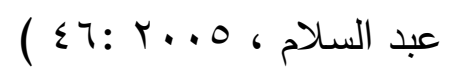

تعمل المساندة الاجتماعية أيضاً على الحفاظ على الوحدة الكلية للصحة الجسمية و النفسية و العقلية للوصول إلى تعزيز و دعم إحساس المنلقي بالراحة النفسية و الاطمئنان في حياته و الثعور بالسعادة 'و و 
تتمي أنماط التفاعل الاجتماعي الإيجابي من الأصدقاء و نزيل أي نوعية من الخلافات ، و تتمي مشاعر

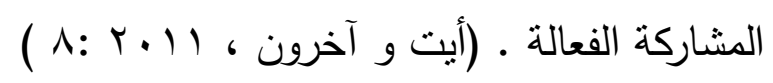

و يؤكد كثير من الباحثين على أن المساندة المدركة أو المساندة المقدمة عن طريق العلاقات الاجتماعية و تعلم المهارات الاجتماعية من العوامل المهمة التي تقي الفرد من العديد من الاضطرابات النفسية و التي قد

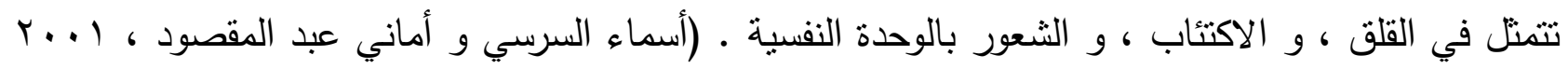
: r و هذا ما دعا الباحثة إلى الاهتمام بالكثف عن علاقة المساندة الاجتماعية بالخجل في الدراسة الراهنة و نظراً لندرة الدراسات التي تتاولت الخجل مع المساندة الاجتماعية على حد علم الباحثة .

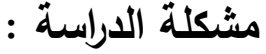

تبلورت مشكلة الدراسة الحالية من خلال ملاحظة الباحثة أن الخجل يمثل مشكلة أساسية على الأخص في مرحلة المراهقة مما يؤدي إلى عدم توافقهم على المستوى النفسي و الاجتماعي و المهني و يحرمه من

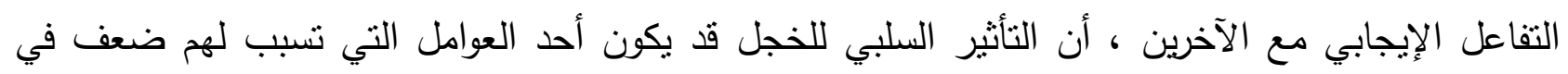
التحصيل ، فغالبية الطلبة الخجولين يعيشون بصفات مشتركة و هي قلة الحركة و عدم التفاعل مع الدرسين

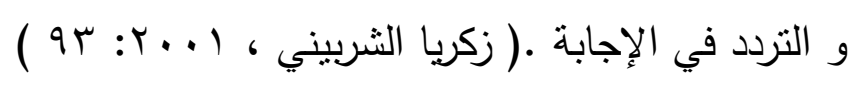

و نظراً لأن الفتيات أكثر تأثراً بالتغيرات التي تطرأ عليهن في مرحلة المراهقة حيث نتودي بهم إلى مشكلات و اضطرابات نفسية منها الخجل ، لذا فهم بحاجة إلى الدعم و المساندة من المحيطين بهم خاصة

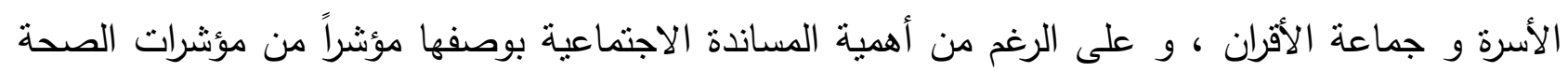
النفسية إلا أنه لا توجد دراسات أجنبية و عربية اهتمت بدراسة هذا المتغير مع الخجل على حد علم الباحثة مما دعا الباحثة إلى القيام بهذه الدراسة ـ وبناء عليه تتحدد مشكلة البحث في الإجابة على السؤال التالي : - هل يوجد علاقة أرتباطية بين الخجل و المساندة الاجتماعية لدى المراهقات ؟

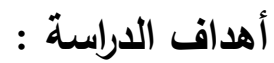

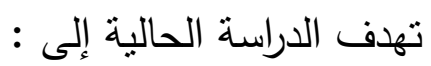
- تحديد العلاقة الأرتباطية بين المساندة الاجتماعية و الخجل لدى المراهقات . 


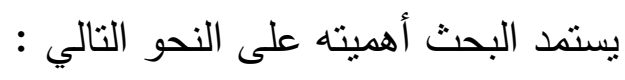

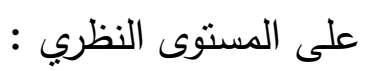
1- تعد هذه الدراسة إضافة علمية للدكتبة النفسية و ذللك لندرة الدراسات التي تتاولت الدساندة الاجتماعية مع الخجل على حد علم الباحثة . - ملى r- التأكيد على دور المساندة الاجتماعية الإيجابي كمؤشر من مؤشرات الصحة النفسية . ب- أهمية الفئة العمرية التي نتاولتها الدراسة و هي مرحلة المراهقة لما لها من دوراً مهماً في تكوين الثخصية.

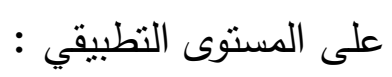
1- يمكن الاستفادة من الدراسة الحالية في التخطيط ووضع البرامج الإرشادية للحد من درجة الخجل لاى المراهقات . r- الاستفادة من الدراسة في مجال التربية والتعليم عند وضع البرامج و الأنشطة الخاصة بالمراهقات و الاهتمام بتدريب المرشدين في المدارس على كيفية حل مشكلات المراهقات و التعامل معهن في ضوء الدراسة r- تقديم برنامج يفيد المربيين و المعلمين و أولياء الأمور في تعاملهم مع المراهقات .

\section{مفاهيم الدراسة :}

\section{1- المساندة الاجتماعية :}

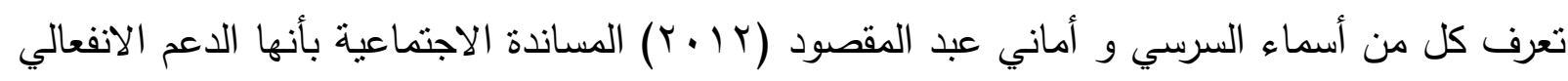
و المادي والأدائي الذي يثلقاه الفرد من قبل الآخرين المحيطين به - الأسرة ، الأصدقاء ، الجيران ، زملاء

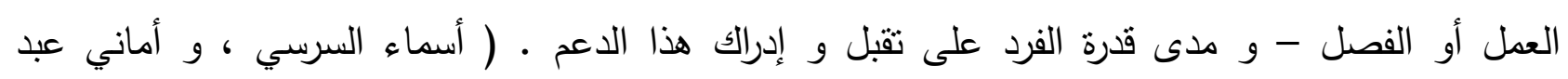

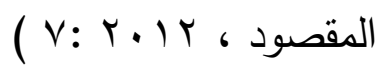


و تعرفها الباحثة إجرائياً بأنها " الدرجة الني تحصل عليها الفحوصة على مقياس المساندة الاجتماعية

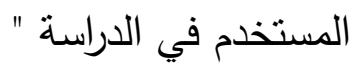

عرف الدريني (991) الخجل بأنه الميل إلى تجنب التفاعل الاجتماعي ـ مع المشاركة في المواقف الاجتماعية بصورة غير مناسبة و يكون الخجل مصحوباً بعدة مظاهر منها الثعور بالقلق و عدم الارتياح و

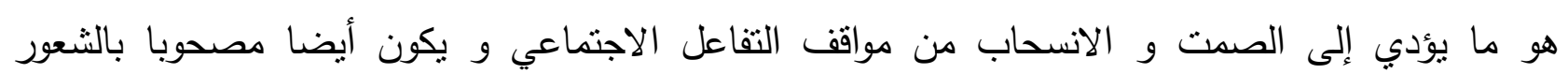

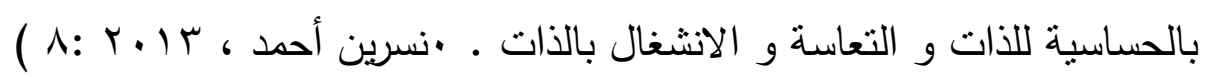

و تعرفه الباحثة إجرائياً بأنه " الدرجة التي تحصل عليها المفحوصة على مقياس الخجل المستخدم في الدراسة

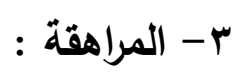

يعرف إبراهيم وجيه ، (1911 ) المراهقة بأنها هي الفنتة التي ثلي الطفولة و تقع بين البلوغ الجنسي و

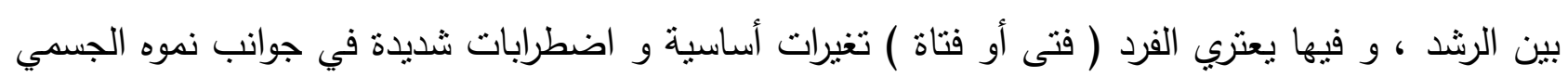

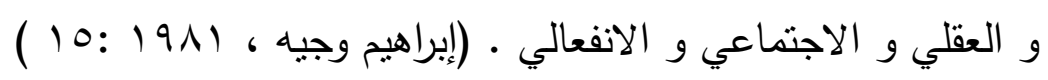
و تعرف الباحثة المراهقة بأنها هي فتزة انتقالية يتجه فيها الفرد تدريجياً من مرحلة الطفولة إلى النضج البدني و العقلي و الاجتماعي و الانفعالي • و يمر من خلالها بعدة تغيرات مهمة التي قد تؤدي بدورها إلى اضطرابات و مشكلات نفسية قد تعصف بحياة المراهق إذا لم يجد الدعم و المساندة ممن حوله . الإطار النظري للادراسة : (2) أولاً : المساندة الاجتماعية :

المساندة تعني المساعدة و المؤازرة و العطاء و الإمداد ، فالإنسان بوصفه كائن اجتماعي يحب الحياة في وسط جماعة لكي يستمد منها الأمن و الطمأنينة و المساندة ، لذا فالمساندة الاجتماعية تعتبر مؤشر من ولن

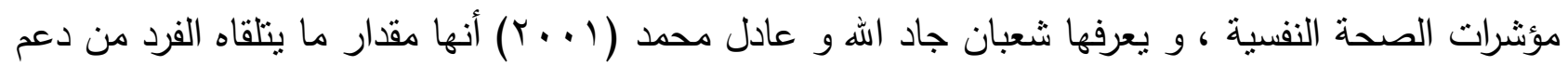
وجداني و معرفي و سلوكي و مادي من خلال الآخرين في بيئته الاجتماعية ـ ( شعبان جاد الله ، و عادل

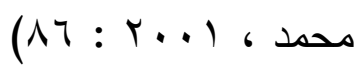


تعمل المساندة الاجتماعية على إثباع الحاجات الأساسية للفرد من حب و احترام و تقدير و تفهم و وان تواصل و تعاطف و مشاركة الاهتمامات و تقديم النصيحة و تقديم المعلومات ، ذللك من الأثخاص ذوبي

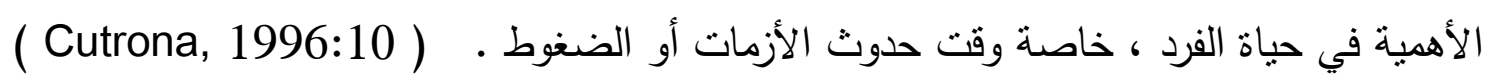

أما علي عبد السلام فيعرف المساندة الاجتماعية على أنها الدعم المادي و العاطفي و المعرفي الذي يستمده الفرد من جماعة الأسرة أو زملاء العمل أو الأصدقاء في المواقف الصعبة التي يواجهها في حياته ، و و تساعده على خفض الآثار النفسية السلبية الناشئة عن تلاك المواقف ، و نساهم في الحفاظ على صحته النفسية

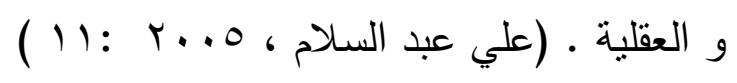

و يرى Moss أن المساندة الاجتماعية هي الثعور الذاتي بالانتماءو القبول و الحب و الثعور بأن الأفراد

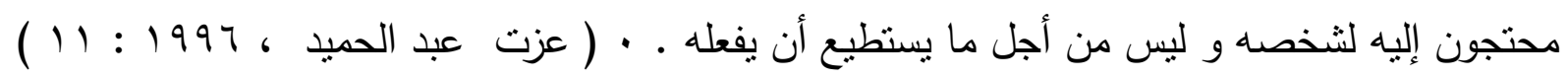
أبعاد المساندة الاجتماعية : يرى كل من محمد محروس الثناوي و عبد الرحمن أن هناك أربعة أبعاد رئيسية للمساندة الاجتماعية و هي: 1- المساندة بالتقدير : و تثمل أن ننقل للآخرين أنهم مقدرون لقيمتهم الذاتية و تسمى المساندة الذاتية . ז- المساندة بالمعلومات : و تتشمل إعطاء الفرد معلومات لتساعده في حل المشكلات و تسمى بالتوجيه المعرفي أو النصح . r- الصحبة الاجتماعية : و نتشمل قضاء بعض الوقت مع الآخرين في أنشطة الفراغ و الترويح و تسمى مساندة الانتثار و الانتماء .

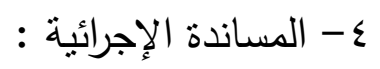


و تثمل تقديم العون المالي ، و الإمكانات المادية و الخدمات اللازمة و قد يساعد العون الإجرائي على

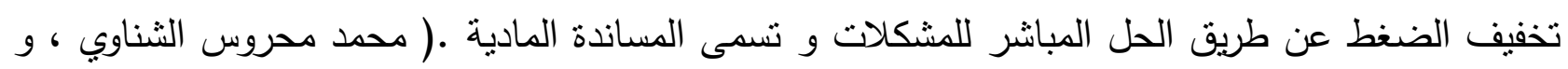

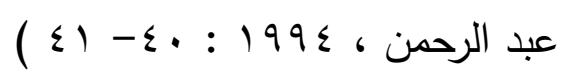

وظائف المساندة الاجتماعية :

للمساندة الاجتماعية عدة وظائف نوجز منها :

1- تعتبر المساندة الاجتماعية مصدر هام من مصادر الأمن النفسي لدى الأفراد العاديين ، و عامل من عوامل إثباع احتباجاتهم الثخصية و الاجتماعية و تساهم في نوافقهم النفسي و الاجتماعي • (عواطف صالح ( $1 \wedge r:$ r...

ץ- تساعد المساندة الاجتماعية الفرد على التعامل مع تهديدات الحياة و التغلب عليها ، و خفض الضغوط

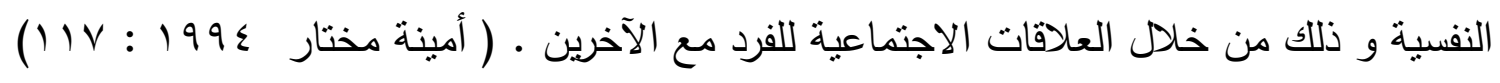
ب- تعمل المساندة الاجتماعية على وقاية الفرد من الآثار النفسية السلبية لأحداث الحباة الصعبة. ع- و يشير Breham إلى أن المساندة الاجتماعية تقوم بمهمة حماية تقدير الثخص لذاته و تشجيعه على مقاومة الضغوط التي تفرضها عليه أحداث الحياة المؤلمة ـ (عماد علي عبد الرازق ـ 1991 1 : 19 ) ع - للمساندة الاجتماعية أهميتها في الحياة المدرسية حيث تعمل على زيادة الدافعية و القدرة على الإنجاز

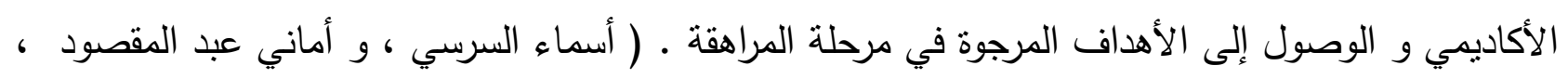
$(199:$ : $\ldots)$

0- للمساندة الاجتماعية دوران أساسيان في حياة الفرد : دور إنمائي و دور وقائي ، و يتمنل الدور الإنمائي في أن الأفراد الذين لديهم علاقات اجتماعية مع غيرهم هم أفضل من ناحية الصحة النفسية ممن ليس لديهم

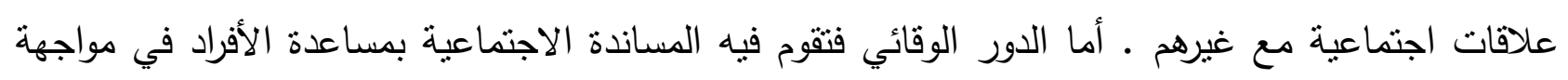
الحياة الضاغطة بأساليب إيجابية و فعالة . 
يرغب الإنسان دائماً في الانتماء إلى جماعة يحقق من خلالها أهدافه و طموحاته و يشعر من خلالها

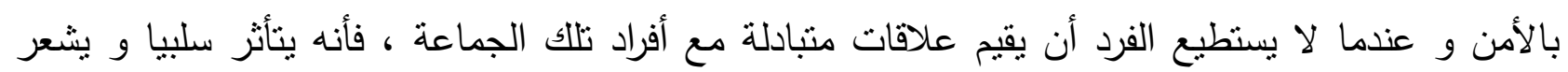

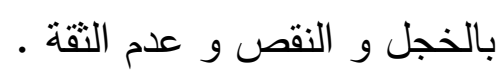

و يشير (2001) Zimbarido إلى أن هناك عدداً من الأفراد يصبحون خجولين عندما يصلون إلى

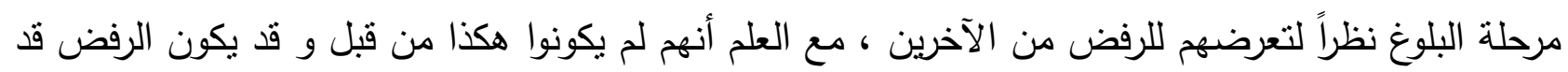

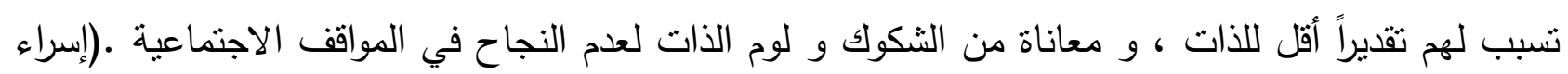

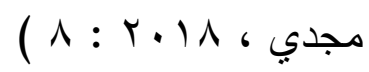

ويرى كل من ويلر ( Wheeler ) و ريس (Reis) أن أحداث ماضية في فترة الطفولة قد نسبب الثعور بالوحدة النفسية في فترة المراهقة ، كما أن الثعور بالوحدة النفسية مرتبط بالخجل ، لذا يعتبر الخجل سمة من

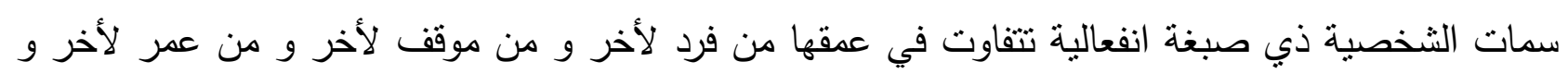

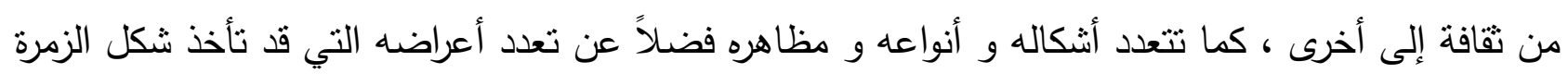

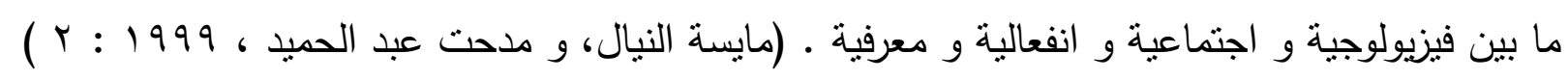
فالخجل أصبح من المشكلات النفسية المهمة في مرحلة المراهقة لأن المراهق الخجول يفتقد المهارات

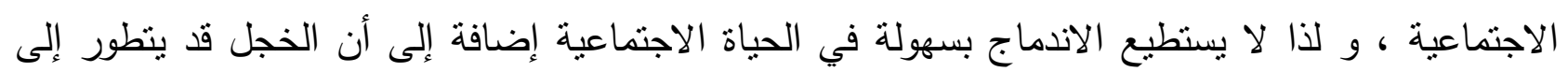

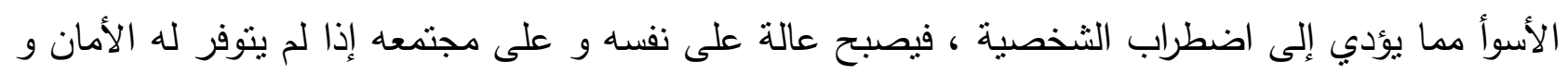

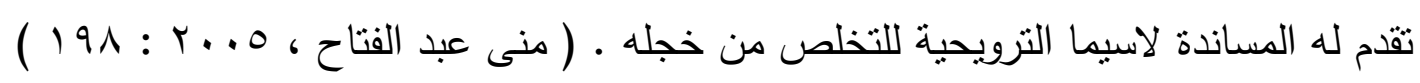
و نجد أن الثخص الذي يعاني من الخجل يفتقر إلى الثقة في النفس و يجد صعوبة في الاندماج مع زملائه و يفتقر إلى الكثير من المهارات الحياتية و الخبرات الجديدة التي يمكن اكتسابها نتيجة للاندماج في المواقف الاجتماعبة كما تتعكس آثار هذا على مستوى التحصيل مما يتغلب عليه الثنعور بالفشل و قد يكون

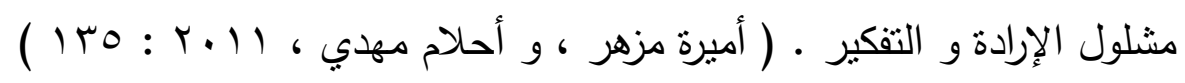
كما أتفق عدد من الباحثين على أن الخجل يتضمن القلق و الارتباك أثناء التفاعلات الاجتماعية ، وتجنب الششاركة الاجتماعية ، و التردد و الخوف من التقدير السلبي ، و الانشغال بالذات و الثنعور بالنقص و الحذر 
و التلعثم و التتتت ، و تؤدي هذه الأعراض كلها إلى عدم التوافق نفسياً و اجتماعياً . ( مايسة النيال ، و

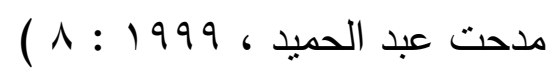

مما سبق بتضح أن الخجل في حد ذاته مشكلة معقدة أو كما يعده كثيراً من علماء النفس مرضا نفسياً و

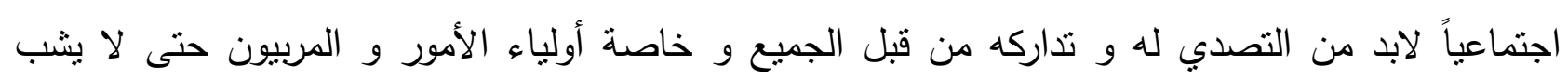

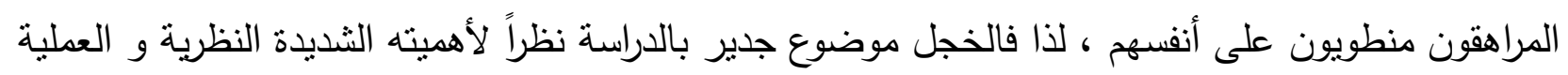
مكونات الخجل :

تمنتلت مكونات الخجل فيما يلي : n

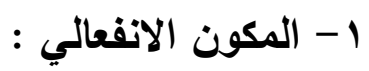

و يظهر من خلال تتبيه الأحاسبس النفسية التي تدفع الفرد إلى استجابة التفادي و الانسحاب بعيداً عن مصدر

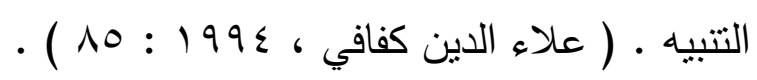

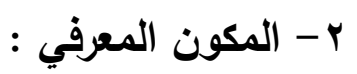
حيث أثنار أيزنك و أيزنك إلى ذلك المكون بأنه انتباه مفرط للذات ، و وعي زائد للذات و صعوبات في الإقناع

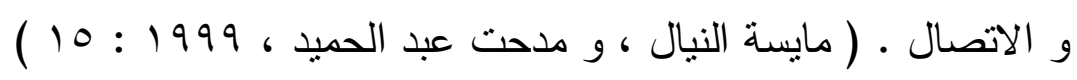

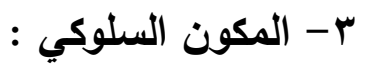

هو نقص السلوك الظاهر و يركز على الكفاءة الاجتماعية للأشخاص الخجولين و يتصفوا بنقص في

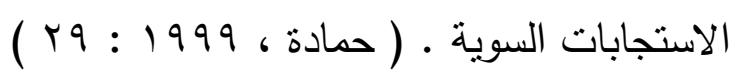

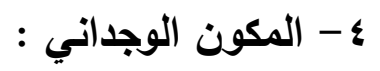

يتمثل في الحساسية ، و ضعف الثقة بالنفس اللحظي و الاستثارة النرجسية و اضطراب المحافظة على الذات .

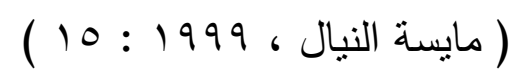


و يتمنل في زيادة ضربات القلب و جفاف الفم و الارتجاف و الثراهة في الأكل عندما يتعرض الثخص

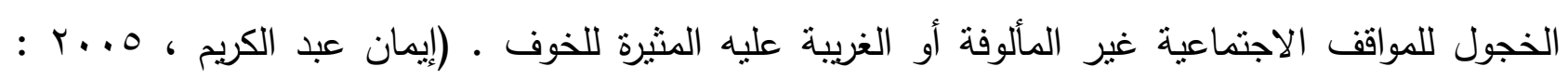

صنف الثربيني الخجل إلى ستة أشنكال على النحو التالي :

1 - 1 - 1جل مخالطة الآخرين :

يأخذ الخجل شكل النفور من الزملاء أو الأقارب أو امتتاع أو تجنب مخالطة الآخرين و تعمد الابتعاد عن

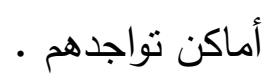

$$
\text { r }
$$

يجيد الطفل الخجول الالتزام بالصمت و عدم التحدث مع غيره و نقص إجاباته على القبول أو الرفض و إعلان

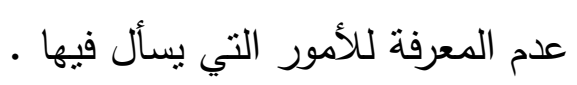
ץ- خجل الاجتماعات :

في حالات نادرة يكتفي الطفل بالحديث مع أفراد الأسرة و بعض زملاء المدرسة و يبتعد عن المشاركة في أي

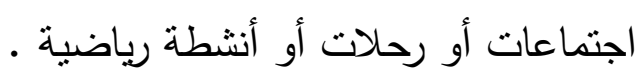

\section{خجل المظهر :}

هناك بعض المواقف التي يظهر فيها الخجل لدى بعض الأطفال ، كأن يخجل عندما برتدي ثوباً جديداً ، أو

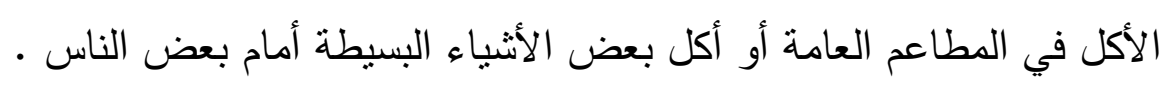

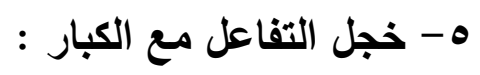

يخجل بعض الأطفال حين يبني حوار بينه أو بين المدرسين أو مدير المدرسة أو عندما يبتاع الطفل أثنياء من

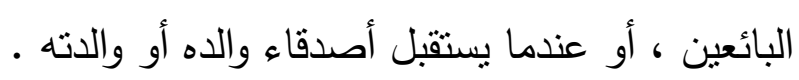


هناك من الأطفال من يخجل من حضور حفلات الأفراح ، أو أعباد الميلاد أو حفلات النجاح و يفضلون

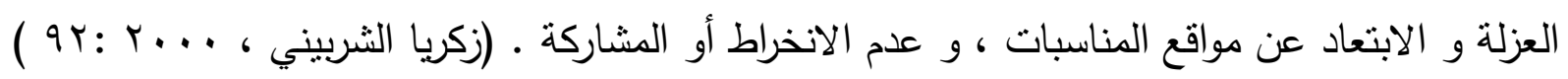

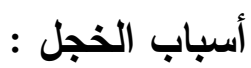
1- ضعف البنية الجسمية : فالهزال الثديد و ضعف بنية الجسم أو النحافة الثديدة تجعل الفرد يتجنب

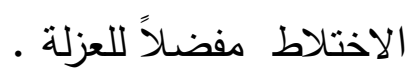

ץ- العاهات و التثوهات : العاهات و التشوهات الجسدية مثل السمنة الدفرطة و طول القامة الثنديد أو قصر

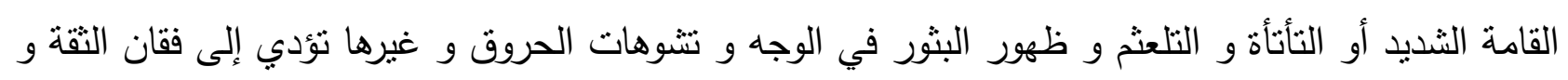
الشعور بالدونية و من ثم الابتعاد عن الآخرين •

r- الضعف العقلي : يتجنب الثخص ذو القدرات الضعيفة المواقف الاجنماعية .

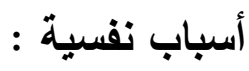

1- الحساسية الزائدة : يتأثر الطفل أكثر من اللازم بالأحداث و يبالغ مبالغة لا معنى لها في تلقي الأحداث و يعطي للأشياء صدى لا تستحقه .

ץ- السعي إلى الاستحسان : يبحث الثخص الخجول دوماً عن الوسائل التي يثير بها استحسان الناس و

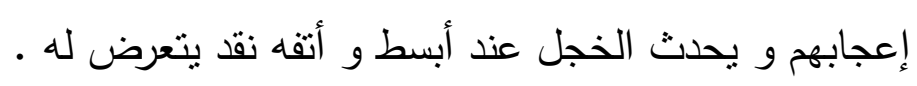

r- اجترار الأحداث المخزية : خبال الطفل الواسع يجعله يتأثر بما سبق له من تجارب الفشل و الحوادث التي

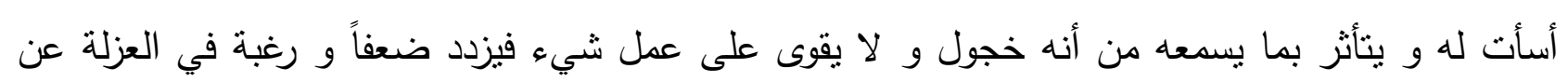
الناس .

ع - التردد و الجمود : وهما من المكونات التي تتعاون في تثكيل ظروف شخصية و اجتماعية فينمو الخجل و يزداد إلى أن يسيطر على النفس و يشل فاعليتها و يقتل الرغبة في الإبداع و الإنتاج . 
تلعب البيئة دوراً كبيراً في حدوث الخجل و تطوره ، حيث ينعرض الفرد لبعض الخبرات الألبمة أو ضغوط

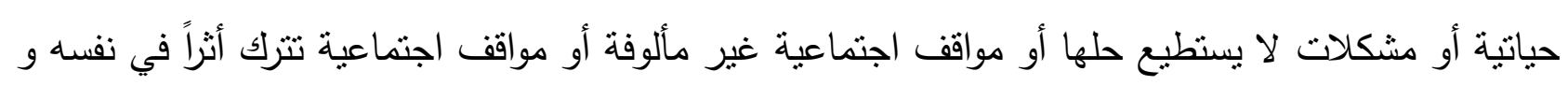
من ثم يجد الفرد نفسه كارهاً للحياة ، زاهداً فيها فيفضل حياة العزلة و الانسحاب ثم يصبح خجولاً غير قادراً على مواجهة الآخرين ، و من العوامل التي تساهم في حدوث الخجل بدور كبير ، العوامل الأسرية و التي لهي

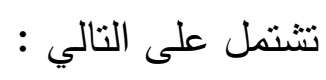
- نشأة الطفل في أسرة منعزلة . - أساليب التنشئة الخاطئة .

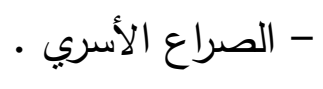

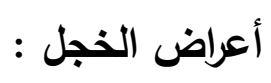
- أعراض فسيولوجية : و منها على سبيل المثال :

احمرار الوجه ، و جفاف الحلق ، شحوب لون الوجه ، زيادة إفراز اللعاب ، الرغبة في بلع الريق مراراً ، و زيادة إفراز العرق ، زيادة خفقان القلب ، و اضطراب العدة ، و و ارتعاش الوجنات و الأطراف والجفون أحياناً . r- أعراض اجتماعية : و منها على سبيل المثال و ليس الحصر : التصرفات السلبية ، تجنب التخاطب بالعين ، و تحاثي تكوين صدقات جديدة ، و تفضيل الانسحاب و العزلة ، و عدم الرغبة في التواصل مع الآخرين .

r- أعراض انفعالية و وجدانية : مثل الثعور بالخوف و الرغبة في البكاءو النوتر ، و الثعور بالضيق و الغضب و التردد و الارتباك و الثعور بالقلق و ضعف الثقة في النفس و الآخرين .

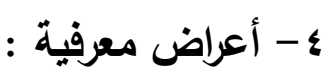

مثل ضعف التركيز و انشغال الفكر بأفكار غير صحيحة و عدم القدرة على إدراك الأمور على حقيقتها و

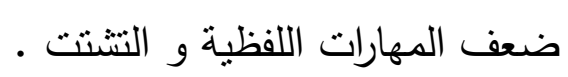


ترى الباحثة من خلال العرض السابق أن الخجل يؤدي إلى فقدان الثقة بالنفس و عدم القدرة على

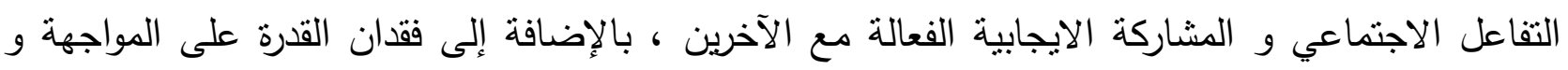

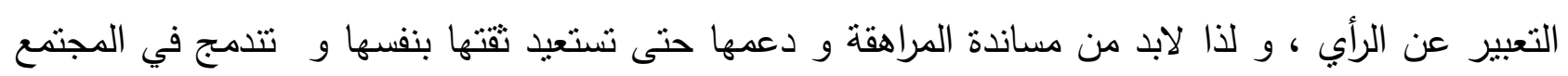

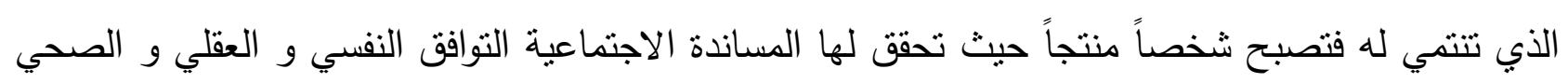

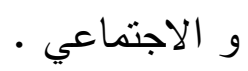

ثالثاً : المراهقة : n

تتميز فترة المراهقة بظهور أزمات كثيرة بسبب التغيرات الفسيولوجية المؤدية إلى النضج الجنسي و

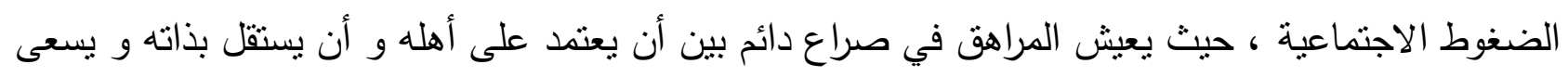
دائماً إلى تجريب قيم و أفكار و سلوكيات جديدة حتى يحدد هويته ــ و تتقسم مرحلة المراهقة إلى ثلاث مراحل

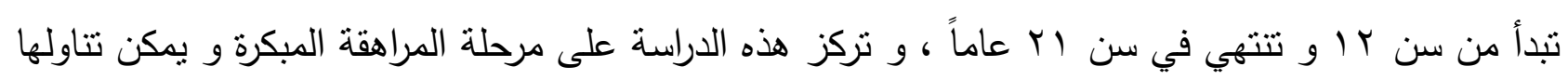
على النحو التالي : بن بن

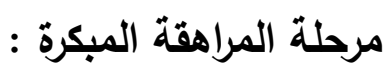

أتفق عليها الباحثون إنها تتزاوح بين r I : ع 1 سنة و تتميز بتناقص السلوك الطفلي و بداية علامات النضج في الظهور و اكتمال وظائفها عند الذكر و الأنثى ، ففي بداية هذه المرحلة تحدث تغيرات عديدة

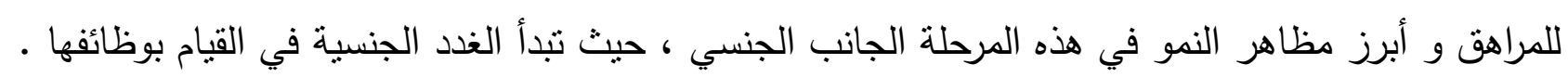

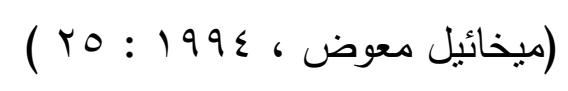

من أبرز ملامح هذه المرحلة بالنسبة للمراهقات :

1 - تقلب المزاج ، حيث تصبح الفتاة في هذه المرحلة أكثر رقة و تغلب عليها العاطفة. r- كثرة معارضة الوالدين و النطاول عليهم أحياناً و عدم الإنصات لهم · r- التأثر بالأصدقاء و تقليدهم في اللبس أو في طريقة الكلام أو في أسلوب الحياة . ع - تعاني بعض المراهقات من عدم الثقة ، حيث تلجأ بعضهن إلى البحث عن أحد غير أهلها لتتسجم معهم. 0- تعاني معظم الفتيات المراهقات من الحساسية و الانطوائية في هذه المرحلة . 
צ- معدل النمو الجسمي لدى البنات يزدد في هذه المرحلة ، فيبدأ بسن r أعند البنات ثم يبطئ تدريجياً عند

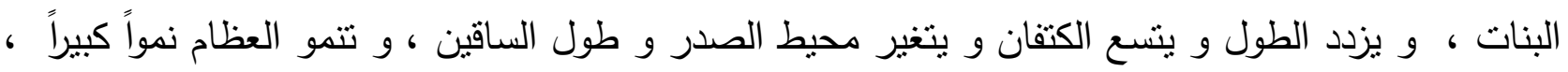
و يظهر الثعر في أماكن مختلفة في الجسم مما يسبب حالة من الخجل و الانزواء لديهن .

V- تتميز هذه المرحلة بالنمو العقلي الكمي و الكيفي ، فيسرع الذكاء العام في هذه المرحلة و تبدأ عندهم القدرة على تعلم المهارات و المعلومات و ينمو التفكير لايهم .

1- تمر المراهقة في هذه المرحلة بتقلبات مزاجية عديدة ، و تكون غير مستقرة نفسياً و يدور الصراع في نفسها . ن

9- يوجد تضارب لدى المراهقة فهي غالبا ما نكون متأرجحة بين أسرتها و أقرانها ، فتحاول الاعتماد على نفسها حتى تشعر بالاستقلال عن والديها ، و تشعر في هذه المرحلة بشيء من الخوف من الجماعات الكبيرة

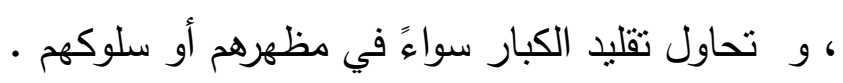

و ترى الباحثة أن المراهقة و خاصة مرحلة المراهقة المبكرة من أصعب المراحل التي تمر بها الفتاة ، حيث تثقى آثارها ملازمة لنخصية الفتاة هدى الحياة ، حيث تتأثر الفتيات أكثر من الفتبان في هذه المرحلة بالتغيرات الفسيولوجية المنمتلة في الدورة الثهرية و بروز الثذيين و النضج الجنسي ، و قد نؤدي هذه التغيرات إلى حدوث صراع داخلي لدى الفتاة مما ينتج عنه اضطرابات نفسية حادة أحياناً و قد يؤدي بها إلى الاكتئاب لئل و الخجل الثديد ، لذا لابد أن يتفهم الوالدين لاحتياجات بناتهن النفسية و العقلية حتى يتم بناء شخصية

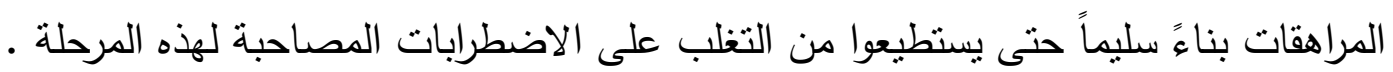

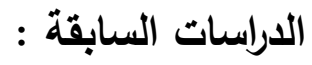

دراسات تناولت المساندة الاجتماعية :

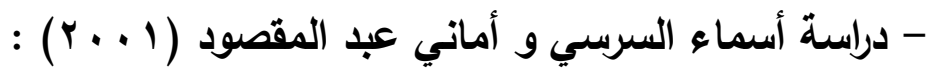

تتاولت الدراسة علاقة المساندة الاجتماعية ببعض المتغيرات النفسية كما يدركها المراهقين ، و تألفت

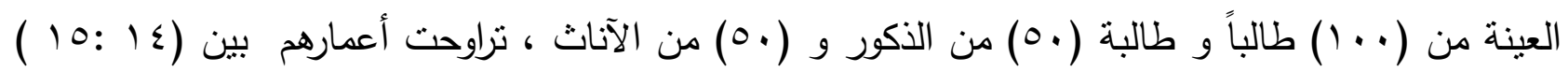

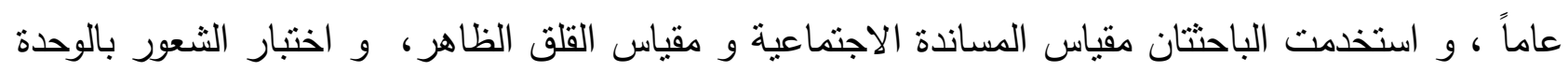
النفسية ، و مقياس الاكتئاب (ز) للصغار ، و مقياس تقدير الذات ، و مقياس دافع الانجاز ، وأسفرت النتائج 
عن وجود علاقة أرتباطية موجبة دالة إحصائياً بين المساندة الاجتماعية و دافع الانجاز و تقدير الذات ، كما توجد علاقة أرتباطية سالبة دالة إحصائياً بين المساندة الاجتماعية و القلق و الثعور بالوحدة و الاكتئاب .

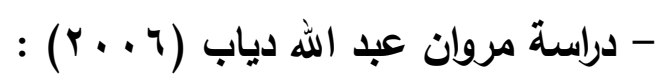

هدفت الدراسة إلى التعرف على دور المساندة الاجتماعية كمتغير وسيط بين الأحداث الضاغطة و الصحة النفسية للمراهقين الفلسطينيين ، تألفت العينة من (00) من الذكور و الإناث ، أستخدم الباحث أستبانة الصحة النفسية ، و أسنبانة المساندة الاجتماعية ، و أستبانة الأحداث الضاغطة ، ، ، أسفرت النتائج عن وجود علاقة عكسية دالة إحصائياً بين درجات الأحداث الضاغطة التي تعرض لها المراهقون و المساندة الاجتماعية ، و وجود علاقة طردية دالة إحصائياً بين درجات الصحة النفسية و درجات المساندة الاجتماعية

: Yue Zhang (2012) دراسة -

هدفت الدراسة إلى معرفة علاقة النطبيع التقافي بالمساندة الاجتماعية و أعراض الاكتئاب لدى عينة من الطلاب الصينيين المقيمين بالخارج ، تألفت عينة الدراسة من (roO) طالباً و طالبة ، و أستخدم الباحث مقياس المساندة الاجتماعية المدركة متعدد الأبعاد ، ومقياس التطبيع التقافي ، و مقياس الاكتئاب ، و أكدت لته النتائج على قدرة المساندة الاجتماعية على خفض الاكتئاب عندما تكون ضغوط التطبيع الثقافي مرتفعة . : Genevieve et al (2015) دراسة -

تتاولت الدراسة العلاقة بين المساندة الاجتماعية و الحماية من الاكتئاب لدى المراهقين و الأطفال والكبار ، و شملت الدراسة (Tr ) عينة من دول مختلفة و تراوحت أعمارهم ما بين 1 أفأكثر ما عدا دراستان إحداهما شملت

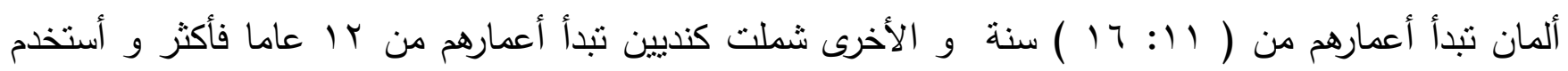
الباحثّن مقياس الاكتئاب و مقياس المساندة الاجتماعية ، و أسفرت النتائج عن نجاح المساندة الاجتماعية في حماية الأطفال و المراهقين و الكبار من الاكتئاب .

\section{: Fatimah Sabouripour \& Samsilah Bte Rostan (2015) دراسة -}

هدفت الدراسة إلى معرفة العلاقة بين المرونة و التفاؤل و المساندة الاجتماعية لدى عينة من التلاميذ

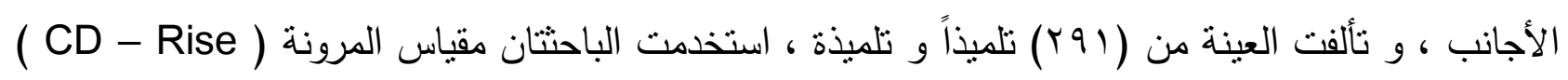


و، و مقياس التفاؤل (Lot - R) ، و مقياس المساندة الاجتماعية (MSPSS) ، و و أثنارت النتائج إلى أن المساندة الاجتماعية و التفاؤل مؤشرات جيدة على المرونة .

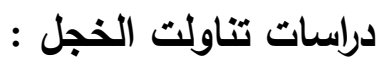

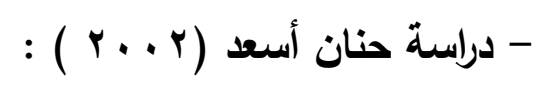
تتاولت الدراسة علاقة الخجل بكل من الثعور بالوحدة النفسية و أساليب المعاملة الوالدية لدى طالبات المرحلة المتوسطة بمكة المكرمة ، و تكونت عينة الدراسة من (ع^乏) طالبة ، استخدمت الباحثة مقياس الخجل المدرسي للدريني ، و مقياس الثعور بالوحدة النفسية للدسوقي (991) ) ، و مقياس أساليب المعاملة الوالدية

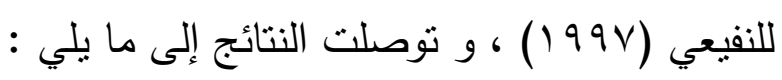

وجدود علاقة أرتباطية موجبة ذات دلالة إحصائياً بين الخجل و الثعور بالوحدة النفسية لاى أفراد العينة ، كما

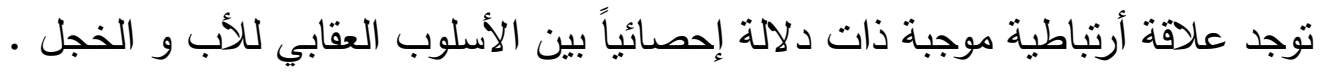

\section{: Lancy D. Souza et al (2008) دراسة -}

هدفت الدراسة إلى معرفة العلاقة بين الخجل و ضرورة الإرشاد بين المراهقين ، تألفت عينة الدراسة

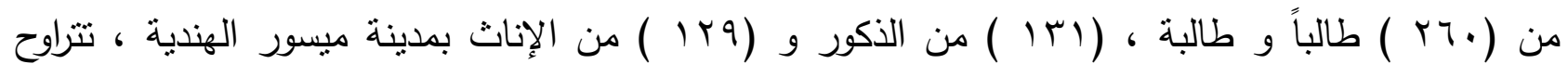

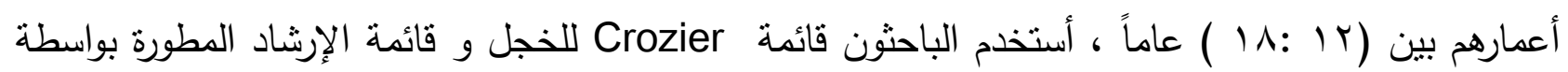
Grewal ، و أفادت النتائج أنه هنالك علاقة طردية بين مستويات الخجل و الحاجة إلى الإرشاد و أن كلما زادت مستويات الخجل ، زاد معها الحاجة إلى الإرشاد .

: Gokhan Bas (2010) دراسة -

تتاولت الدراسة العلاقة بين الخجل و الوحدة بمستوياتها لاى تلاميذ المرحلة الابتدائية في نركيا و تألفت

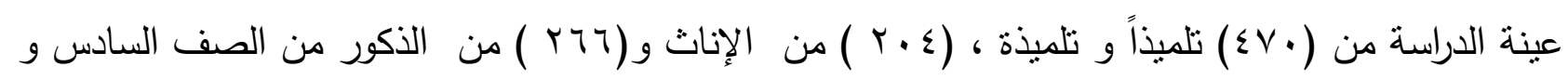

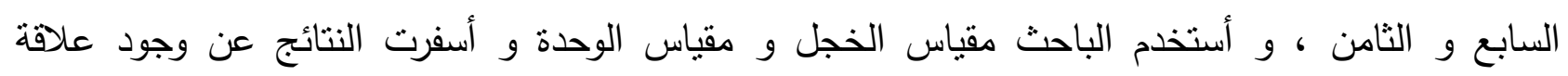
ارتباطية موجبة ذات دلالة إحصائية بين الخجل و الثُعور بالوحدة . 
هدفت الدراسة إلى معرفة العلاقة بين الخجل الاجتماعي و مستوى التحصيل لدى طالبات معهد إعداد المعلمات بمدينة ديالي بالعراق ، و بلغت العينة (•ـ ( ) طالبة ، و استخدمت الباحثتان مقياس الخجل الاجتماعي ومقياس التحصيل الدراسي و معامل ارتباط بيرسون لإيجاد علاقة الخجل بالتحصيل الدراسي و وأسفرت النتائج عن وجود علاقة أرتباطية موجبة دالة إحصائيا بين الخجل الاجتماعي و التحصيل الدراسي لديهن

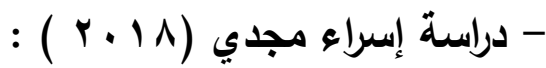

تتاولت الدراسة علاقة الخجل الاجتماعي ببعض الأفكار اللاعقلانية لدى المراهقات ، كما هدفت الدراسة

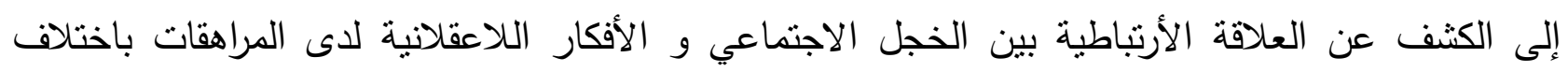

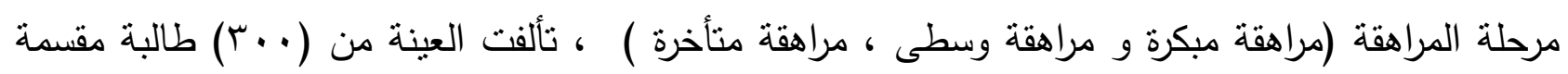
إلى ثلاث شرائح ، الثريحة الأولى ( تمنل مرحلة المراهقة المبكرة ) من طالبات الصفين الأول و الثاني

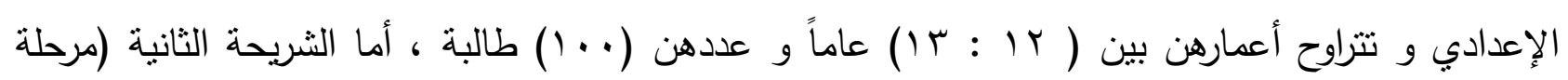

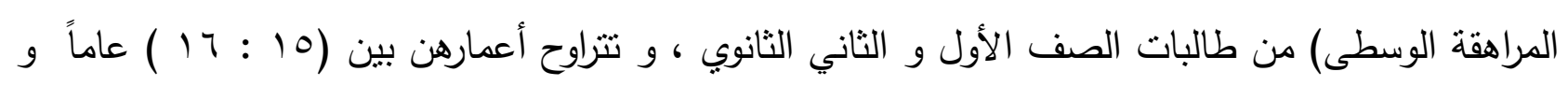

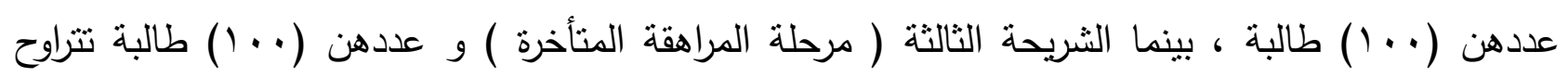
أعمارهن بين (1) : 19 (1) ) عاماً ، أسفرت النتائج عن وجدود علاقة أرتباطية بين الخجل و الأفكار اللاعقلانية للدى المراهقات ، و وجود علاقة أرتباطية بين الخجل و الأفكار اللاعقلانية لدى المراهقات باختلاف مراحل المراهقة .

\section{تعقيب على الدراسات السابقة :}

من خلال العرض السابق للبحوث و الدراسات التي تتاولت المساندة الاجتماعية ، يمكن ملاحظة أن المساندة الاجتماعية لها فوائدها العديدة حيث لها القدرة على زيادة درجة الإنجاز الأكاديمي و زيادة درجة تقدير

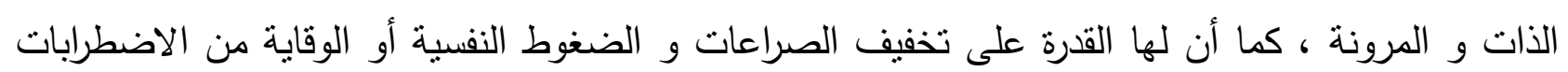
النفسية المتمثلة في القلق و الاكتئاب و الثُعور بالوحدة النفسية ، و على الرغم من ارتباطها بالعديد من المتغيرات إلا أنها لم يتم تتاولها مع متغير الخجل على حد علم الباحثة سواء في الدراسات العببة أو الأجنبية 
من خلال البحوث والدراسات السابقة التي تتاولت الخجل يمكن ملاحظة أن الخجل ينتج عن الأفكار اللاعقلانية ويؤدي إلى الثعور بالوحدة ، كما أن المعاملة الوالدية التي تتسم بالقسوة تؤدي إلى زيادة الخجل ،

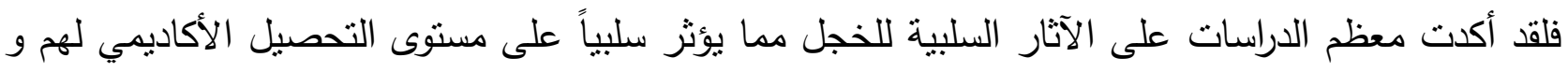
يعوقهم عن التفاعل الإيجابي مع الآخرين لذا فهم بحاجة إلى الدعم و المساندة الاجتماعية من المحيطين بهم للتخفيف من حدة الخجل و لمساعدتهم للتفاعل الإيجابي مع الآخرين ، لذا جاءت أهمية الدراسة الحالية نظراً للاور الإيجابي الفعال للمساندة الاجتماعية حيث نعتبر مؤشر حيوي من مؤشرات الصحة النفسية . رابعاً : الطريقة و الإجراءات :

- منهج الاراسة : تتدرج هذه الدراسة تحت المنهج الوصفي الأرتباطي نظراً لأن طبيعة الدراسة الحالية تحاول الكثف عن العلاقة الأرتباطية بين المساندة الاجتماعية و الخجل . - مجتمع الدراسة: يتكون مجتمع البحث من طلبة المرحلة الإعدادية بمدرسة الهنداو الإعدادية بمحافظة الوادي الجديد . - عينة الداسة : بلغت العينة (T ) طالبة من الصف الأول و الثاني الإعدادي اختيرت بالطريق العشوائية

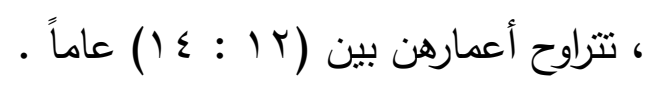
- أدوات الدراسة : n - n

مقياس المساندة الاجتماعية.

Dunn, et al. استخدمت الباحثة مقياس المساندة الاجتماعية الذي أعدته سوزان ديون وآخرون وعربته أسماء السرسي وأماني عبد المقصود ( . . . ب) بهدف تقدير المساندة الاجتماعية، وتكون المقياس من ثلاثة أبعاد فرعية وهي : المساندة من قبل النظراء (الأصدقاء والجيران )، والمساندة من قبل الأسرة، والرضا الذاتي عن المساندة، وتم عرض المقياس على متخصصين في اللغة العربية وعلم النفس، ولتقنين المقياس في صورته 
العربية تم تطبيقه على عينة مكونة من عدد ( . . 1 ) طالب وطالبة من طلاب الصف الأول الثانوي العام؛ حيث أجري له صدق البناء وصدق المحك، وقد تم حساب ثنات المقياس بطريقة ألفا كرونباخ للأبعاد الفرعية

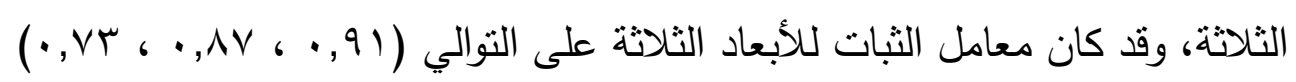

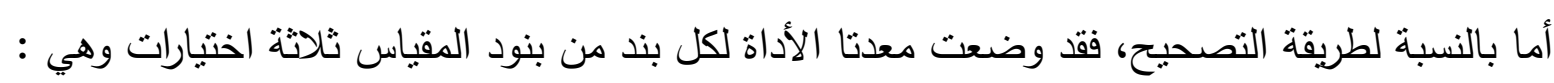

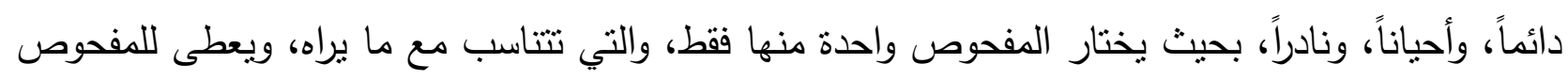

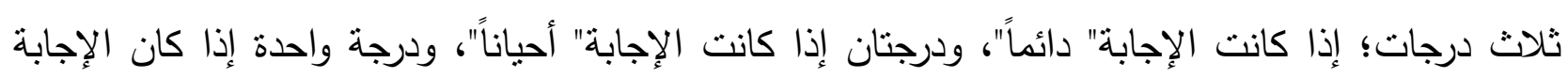

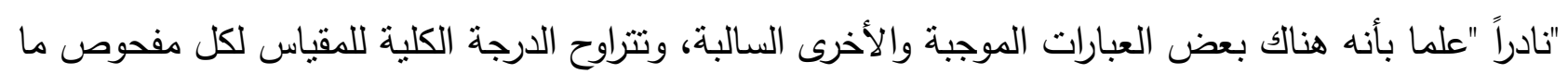
بين (ro - Vo) درجة، وتعكس الدرجة الكلية للفحوص مستوى إدرالك الفرد للمساندة الاجتماعية التي يتلاقها من الأسرة والأصدقاء.

الخصائص السيكومترية للمقياس في الدراسة الحالية:

صدق المحكمين:

عرض الاختبار في صسورته المبلئية على المحكمين : تم عرض المقياس على مجموعة من المحكمين المتخصصين في هذا المجال، لإبداء آرائهم ووجهة نظرهم، وقد قامت الباحثة بحسـاب صدق المحكمين

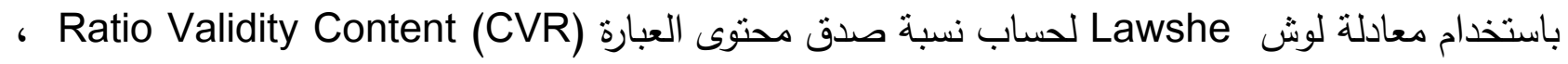
و وجد أن نسب صدق المحكمين على عبارات المقياس بطريقة لوش تراوحت بين (•V, · - ( ) ، وجميعها أكبر من القيمة الحرجة التي حددها لوش للصدق والتي تساوي (rT, • ) مما يثبر إلى صدق المقياس ، و تم عمل بعض التعديلات على تعليمات الاختبار لتكون أكثر وضوح وتعديل صياغة بعض الأسئلة وفقا لرأي المحكمين. الاتساق الاخلي: - n

وتم ذلك من خلال حساب معاملات الارتباط لبيرسون بين درجة كل عبارة والدرجة الكلية للبعد الذي

تتنمي إليه، وكذلك معاملات الارتباط لبيرسون بين درجة كل بعد والدرجة الكلية للمقياس

حيث أن جميع قيم معاملات ارتباط العبارة بالدرجة الكلية للبعد الذي تتنمي إليه دالة إحصائياً عند مستوي ( ا... ) ، وكذلك معاملات الارتبـاط بين كل بعد والدرجـة الكليـة للمقيـاس ويحقق هذا درجة مرتفعة من 
- حساب معامل ثبات الاختبار

يقصد بثات الاختبار درجة الاتساق في النتائج التي تعطيها أداة التقويم إذا ما طبقت على عينة من

الممتحنين أكثر من مرة في ظروف تطبيقية منشابهة.

ولحسـاب معامل الثبات تم استخدام معادلة ألفـا- كرونبـاخ Alpha ، حيث بلـغ معامل ألفـا

للمقياس ككل

(^^^. • • • مما يدل على ارتفاع معامل الثبات و بناء عليه فأن المقياس يتمتع بلرجة مناسبة من

مقياس الخجل

خطوات إعداد المقياس:

مرت عملية بناء الاستبانة بأربع مراحل رئيسية : بدءا من الاستعانة بمجموعة من مقاييس الخجل ،

انتقالا إلي الإجراءات التي اتخذت لتطوير وبناء مقياس الخجل في ضوء الأدب التربوي التي تمت مراجعته

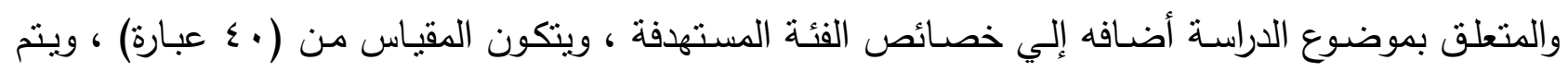
الاستجابة عليها من خلال مقياس ليكرت الخماسي

ويتكون المقياس من أربع أبعاد رئيسية (الفسيولوجي ، الانفعالي ، الاجتماعي ، المعرفي) بواقع (• ( ) عبارات

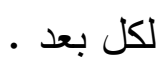

الخصائص السيكومترية لمقياس الخجل صدق المقياس: حيث اعتمدت الباحثة على:

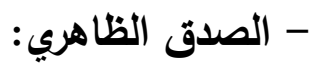

حيث يهنم هذا النوع بالمظهر العام للاستبانة أو الصورة الخارجية له من حيث : نوع المفردات وكيفية صياغتها، ومدى وضوحها ودقتها ، وصحة ترتيبها ، ووضوح التعليمات ، وأيضا ددي مناسبة الاستبانة للهدف الذي وضع من أجله، عليه اعتبر صدق المحتوي مؤشراً لصدق الاستبانة (سعد عبد الرحمن، 991 (، عـ (1). تم عرض المقياس في صورته الأولية علي عدد من المحكمين تم اختبارهم من الخبراء المتخصصين في مجال علم النفس والصحة النفسية؛ وذلك بغية إبداء آرائهم في صلاحية وشمولية العبارات لقياس ما وضعت من أجله 
، ومناسبة سلم التقدير للإجابة، إضافة إلي مدي وضوح صياغة كل عبارة للطالبات، وإمكانية تعديل الصياغة أو حذف أو إضافة عبارات جديدة ، ليصبح المقياس أكثر قدرة علي تحقيق الهدف الذي بني من أجله ، وهذا ما يعبر عن صدق المحتوي، وفي ضوء المرئيات والمقترحات التي أبداها السادة الدكمين تم إجراء التعديلات الآتية:

- استبقيت العبارات التي حصلت علي صدق المحتوي (rTT, · فأعلي وفق محك لوش) بينما عدلت بعض العبارات كما حذفت بعض العبارات وبذللك يتكون المقياس من (•ـ ) عبارة. - إجراء دراسة استطلاعية للتحقق من ثبات وصدق الدقياس بأبعاده بتطبيقه علي عينه من طالبات المرحلة الإعدادية قوامها (· V) طالبة نم اختيارهم بطريقة عشوائية.

- صدق المحك :

تم تطبيـق المقيـاس الحـالي ومقيـاس الخجل مـن إعـداد مايسـة النبـال و مـدحت عبد الحميد علـي العينـة

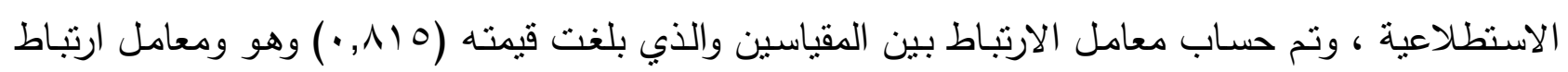
قوي ودال إحصائيا عند مستوي دلالة (1 ... ) مما يدل علي صدق المقياس الحالي .

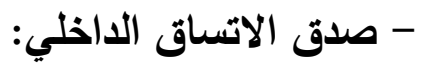

وتم ذلك من خلال حساب معاملات الارتباط لبيرسون بين درجة كل عبارة والدرجة الكلية للبعد الذي تتنمي إليه، وكذلك معاملات الارتباط لبيرسون بين درجة كل بعد والدرجة الكلية للمقياس .

يتضح من الجدولين السابقين أن جميع قيم معاملات ارتباط العبارة بالدرجة الكلية للبعد الذي تتنمي إليه دالة

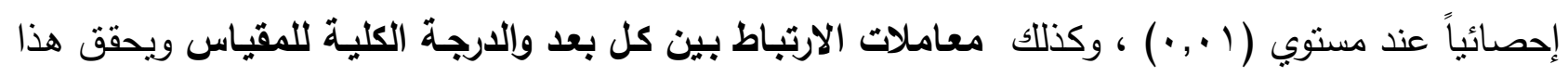
درجة مرتفعة من الاتساق الداخلي للمقياس ·

\section{:Alpha الثبات بطريقه ألفا- كرونباخ}

تم حساب قيمه معامل ألفا للمقياس ككل وبلغت (0.825) وهي قيمة مرتفعة ، وهذا دليل كافي على أن المقياس يتمتع بمعامل ثبات عالي ، وتم أيضا حساب الثبات عن طريق التجزئة النصفية وبلغ معامل سبيرمان بروان للثبات (0.875) ، ومعامل جتمان للتجزئة النصفية (0.872) • 
رابعاً : نتائج الاراسة و تفسيرها :

للتحقى من فرض الاراسة الذي ينص علي "توجد علاقة ارتباطية دالة إحصائيا بين المساندة الاجتماعية والخجل" استخدمت الباحثة معامل ارتباط بيرسون وجاءت نتائجه كما يوضحها الجدول التالي: جدول (؟) معاملات الارتباط بين المساندة الاجتماعية والخجل

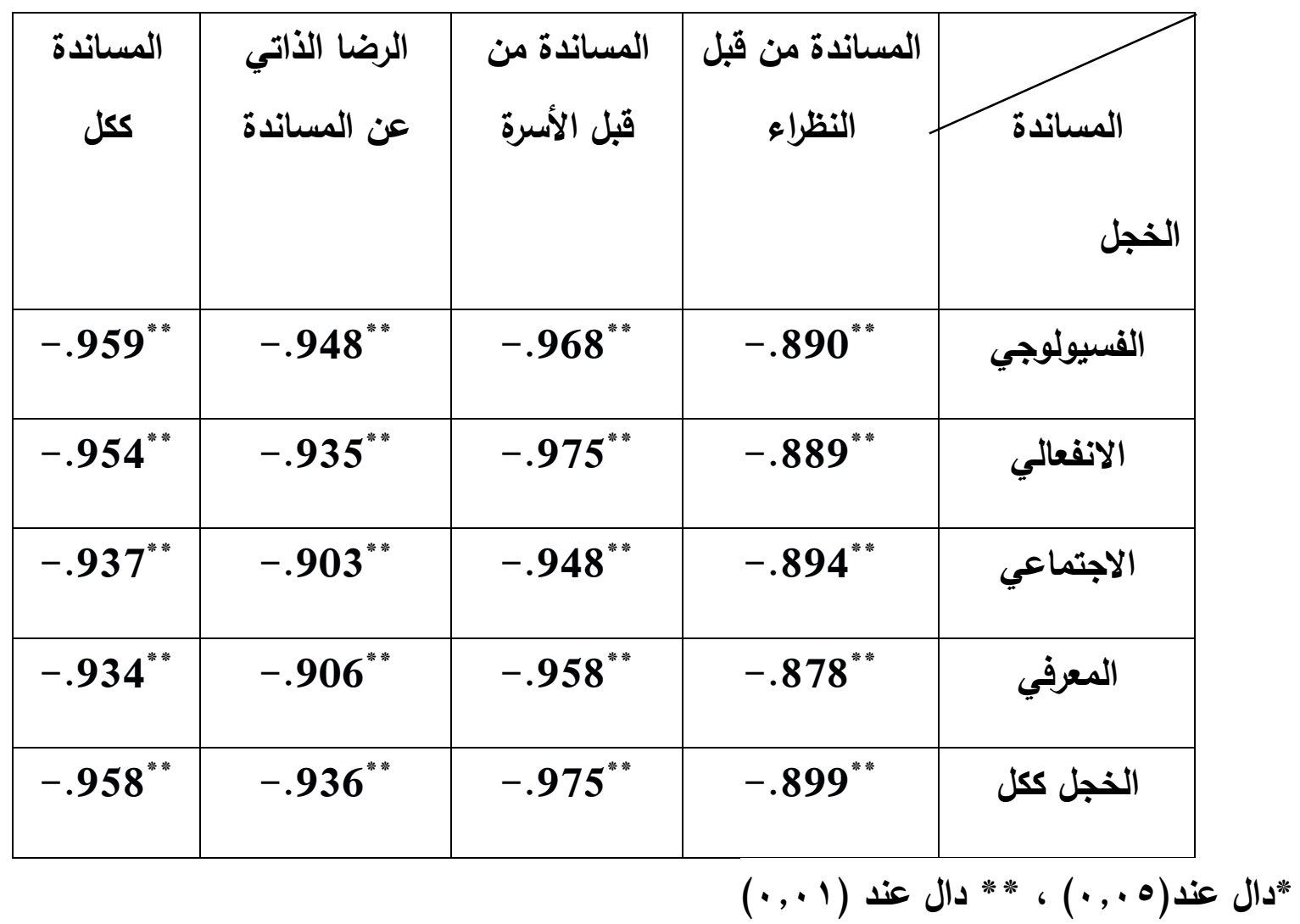

يتضح من الجدول السابق وجود علاقة ارتباطية سالبة دالة إحصائيا بين أبعاد مقياس المساندة الاجتماعية ، ومقياس الخجل وهذه العلاقة مرتقعة ، وبالتالي كلما زادت المساندة انخفض الخجل ، حيث بلغ معامل الارتباط بين البعد الفسيولوجي للخجل و المساندة ككل (959.-) مما يدل على وجود علاقة ارتباطية سالبة دالة

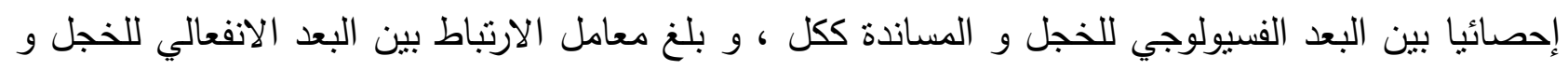
بين المساندة ككل (954.-) مما يدل على وجود علاقة ارتباطية سالبة بين البعد الانفعالي للخجل و المساندة ككل ، بينما بلغ معامل الارتباط بين البعد الاجتماعي للخجل و بين المساندة ككل ( 937.-) ، و يدل هذا لهابل على وجود علاقة ارتباطية سالبة بين البعد الاجتماعي للخجل و المساندة ككل ، و بالنسبة لمعامل الارتباط 
بين البعد المعرفي للخجل و المساندة ككل فقد بلغ (934.-) ، مما يدل على وجود علاقة ارتباطبة سالبة بين

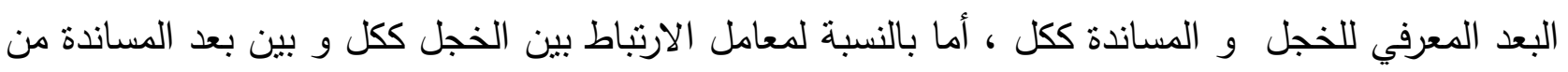
قبل النظراء فقد بلغ (899.-) مما يدل على وجود علاقة ارتباطية سالبة بين الخجل ككل و بعد المساندة من

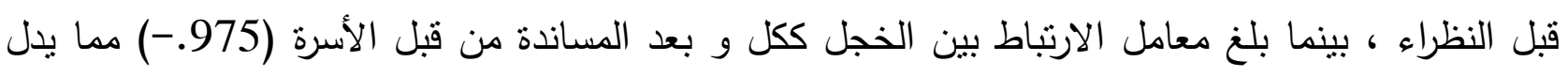
على وجود علاقة ارتباطية سالبة بين الخجل ككل و بين بعد المساندة من قبل الأسرة ، و قد بلغ معامل الارتباط بين الخجل ككل و بين بعد الرضا الذاتي عن المساندة (936.-) ، مما يدل على وجود علاقة

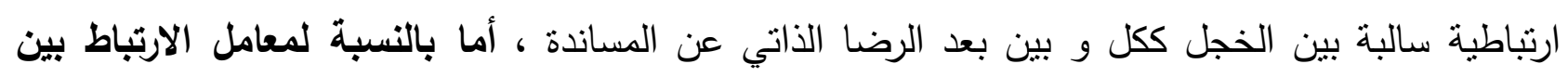
الخجل ككل و المساندة الاجتماعية ككل فقد بلغ (958.-) ، مما يؤكل على وجود علاقة ارتباطية سالبة

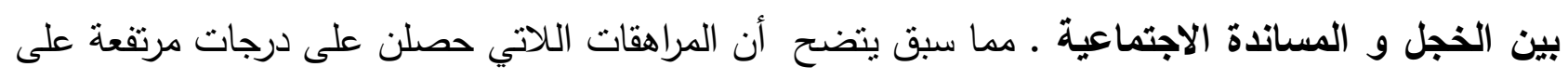
مقياس المساندة ، حصلن على درجات منخفضة على مقياس الخجل مما يدل على الدور الإيجابي و الفعال

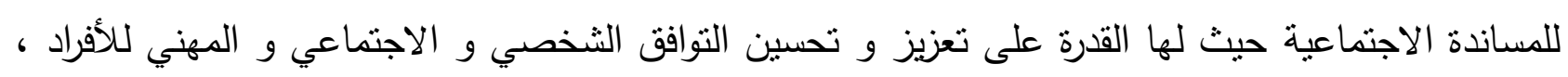

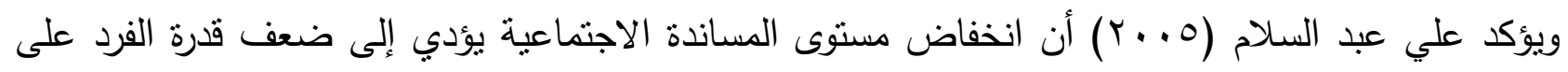
مواجهة الأحداث الضاغطة و بالتالي يصبح الثخص أكثر عرضة للاضطرابات النفسية ، و بما أن الخجل إنل

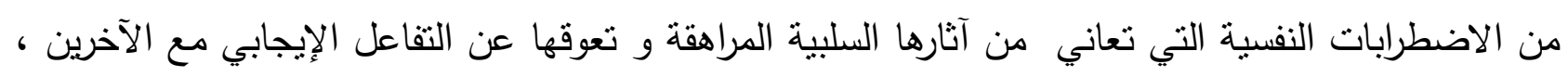

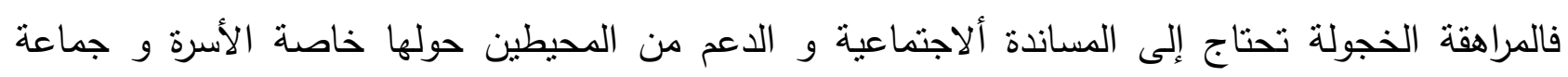
الأقران ، و يرجع ذلك إلى ما تقوم به المساندة الاجتماعية من وظائف عديدة منها : إنباع حاجات الانتماء ،

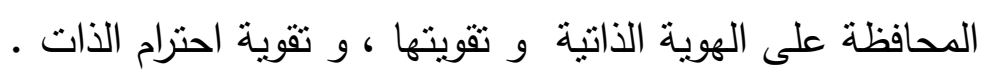

فالمراهقة الخجولة كثثراً ما تعاني من التوتر و القلق و الانسحاب من الحياة الاجتماعية و الوحدة الني

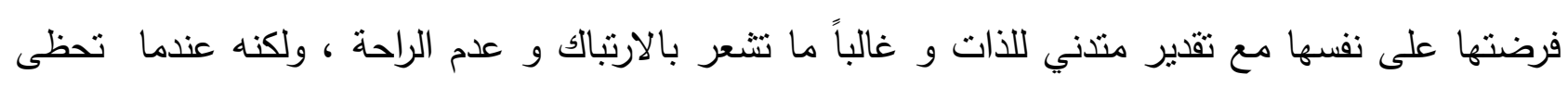

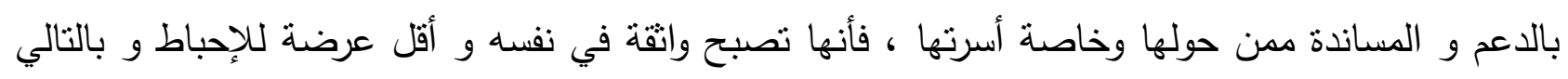
تمتاز بالقدرة على حل مشكلاتها بشكل إيجابي و ينعكس بالإيجاب على تحصيلها الأكاديمي وهذا ما أكدته

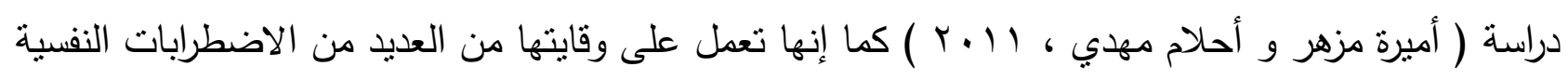

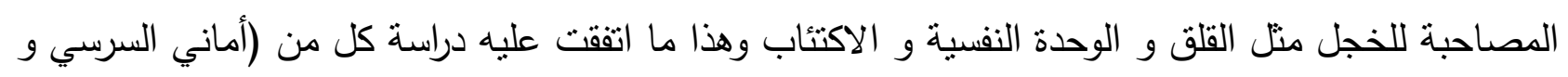

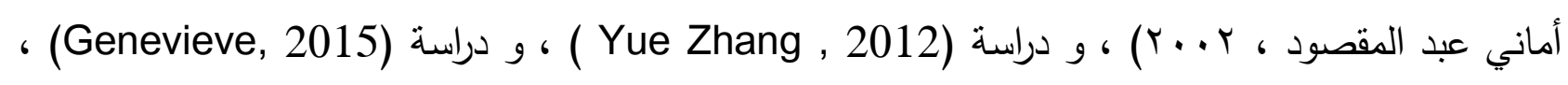


كما أنها تحقق لها التوافق النفسي و الاجتماعي و تزيد من تقديرها لذاتها و هذا ما أكدته دراسة (أيت حمودة و

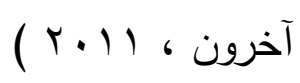

\section{قائمة المراجع العربية و الأجنبية :}

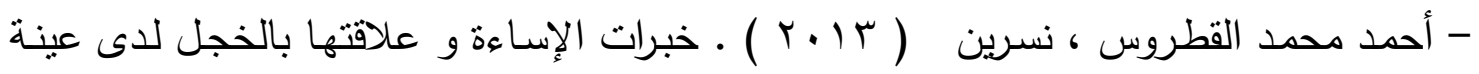
من المراهقين ، رسالة ماجستير، كلية التربية ، جامعة الأزهر بغزة .

- أحمد النيال، مايسة ، و عبد الحميد ، مدحت (999 1) .الخجل و بعض أبعاد الثخصية ( دراسة مقارنة في ضوء عوامل الجنس و العمر و الثقافة ) ، الإسكندرية : دار المعرفة الجامعية.

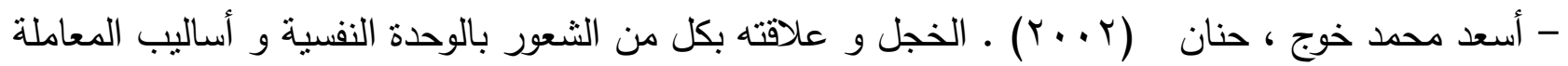

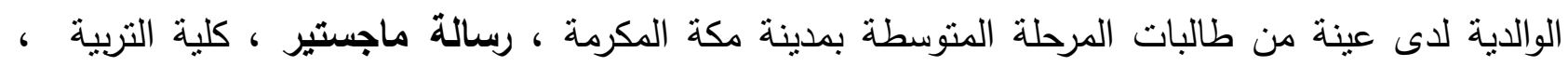
جامعة أم القرى .

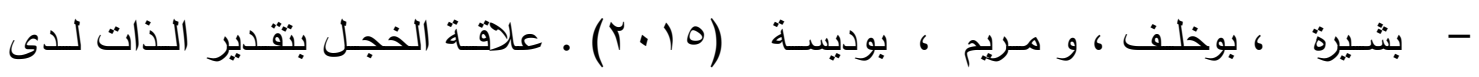
المراهق المتمدرس في السنة الأولى ثانوي ، رسالة ماجستير ، كلية العلوم الاجنماعية و و ولئ الإنسانية ، جامعة البويرة بالجزائر .

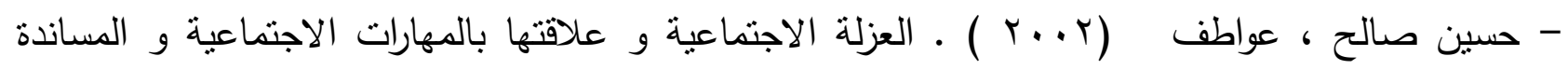

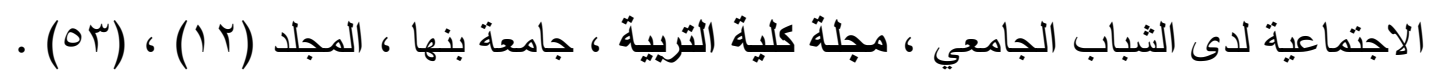
- حمادة ، لؤلؤة ، و عبد اللطيف ، حسن (1999) ـ الخجل من منظور الفروق بين الجنسين و أوجه الاختلاف بين الفرق الدراسية الأربع الجامعية ، مجلة الدراسات الخليج و الجزيرة ، (ع 9) ، إ ا- سبا . .

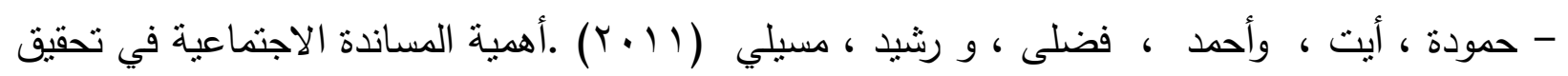
التوافق النفسي و الاجتماعي لدى الثباب البطال، بحث منشور ، مجلة العلوم الإنسانية والاجتماعية،

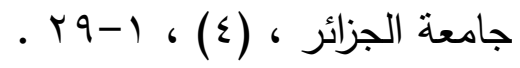




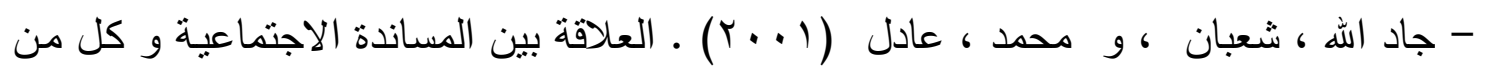
مظاهر الاكتئاب و تقدير الذات و الرضا عن الحياة ـ مجلة علم النفس ، الهيئة المصرية

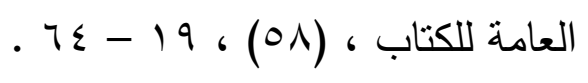

- السرسي ، أسماء ، عبد المقصود ، أماني (1 . . . . المساندة الاجتماعبة كما يدركها المراهقين و علاقتها ببعض المتغيرات النفسية ، بحث غير منشور ، جامعة عين شمس •

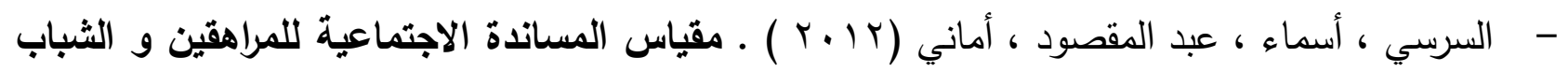
.

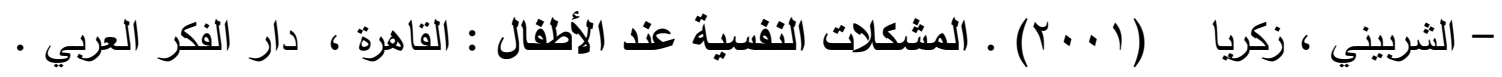
- عبد الحميد حسن ، عزت (997) ( 197 ـ المساندة الاجتماعية و ضغط العمل و علاقة كل منها برضا المعلم عن العمل ، رسالة دكتوراه (غير منشورة ) ، كلية التربية ، جامعة الزقازيق .

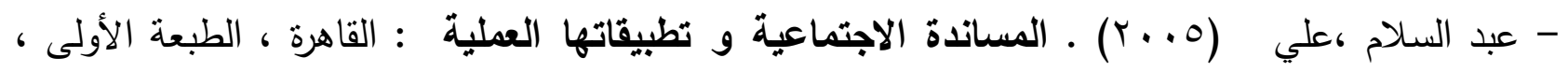
مكتبة الأنجلو - مل

- على عبد الرازق ، عماد (991).المساندة الاجتماعية كمتغير وسيط في العلاقة بين المعاناة الاقتصادية

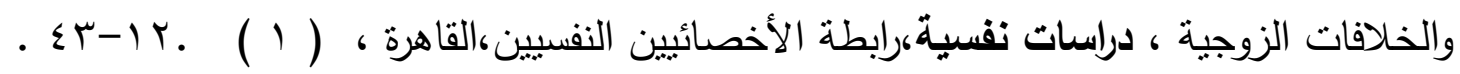

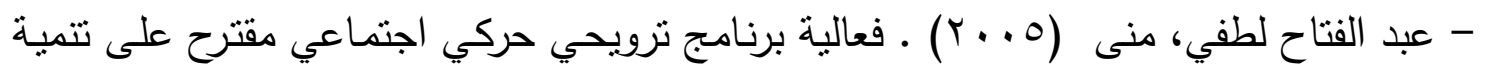
المهارات الاجتماعية و خفض الثعور بالخجل لدى الأطفال في مرحلة الطفولة المتأخرة بمؤسسات الرعاية الاجتماعية ، مجلة دراسات في التعليم الجامعي_، جامعة عين شمس ،

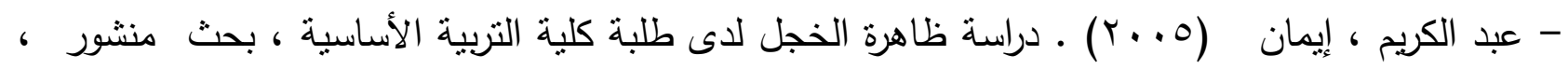

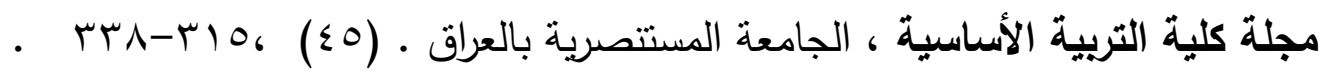
- محروس الثناوي ، محمد ، و السيد عبد الرحمن ، محمد (ع999) ـ المساندة الاجتماعية و الصحة النفسية : مراجعة نظرية و دراسات تطبيقية ، القاهرة : الأنجلو المصرية . 
- محمد مختار، أمينة (ع 199 ) ـ العلاقة بين المساندة الاجتماعية و العصابية لاى المراهقون ، مجلة

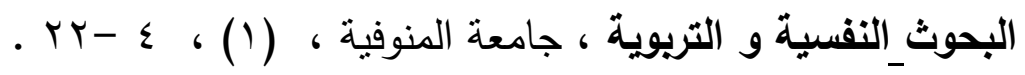

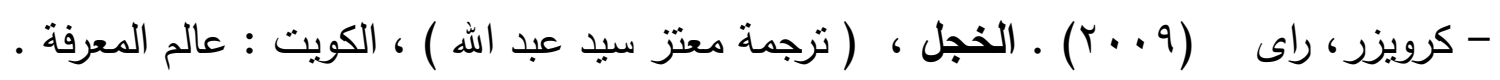
- كفافي ، علاء الدين (99 (1)). معجم علم النفس و الطب النفسي ، القاهرة : دار النهضة العربية .

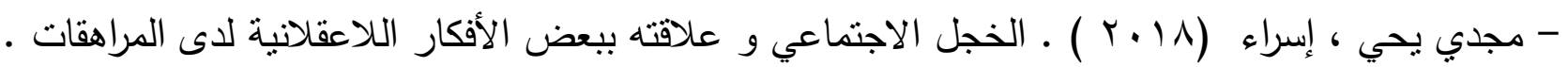

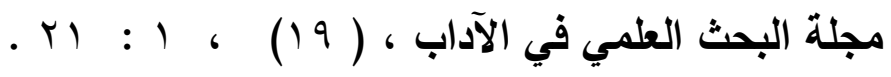

- مزهر ، أميرة ، و مهدي ، أحلام (1) ـ (1) ـ الخجل الاجتماعي و علاقته بالتحصيل الدراسي لدى طالبات

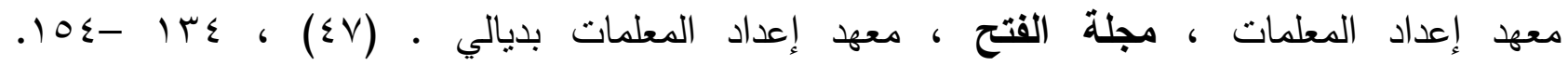
- ميخائيل ،عوض خليل (ع99 1) • سيكولوجية نمو الطقولة و المراهقة ، مصر : دار الفكر العربي . - وجيه محمود ، إبراهيم (1911 ) ـ المراهقة خصائصها و مشكلاتها ـ دار المعارف ، 1 ـ 100. المراجع الأجنبية : n

- Cutrona ,c. (1996). Social Support in couples . London : Sage Publication.

- Bas, G. (2010). An Investigation of Loneliness Levels of Elementary Students in a Turkish Sample,_Journal of Educational Sciences, $2(2), 419-441$

- Gariepy ,G. , Honkaniemi ,H. \& Vallee, A. Q. (2015). Social Support and Protection from Depression : Systematic Review of Current Findings in Western Countries, The British Journal of Psychiatry , 1(10), 1192- 1570

- Souza, L. D. ,Urs, G. B. \& Jayaraju ,R. (2008). Relationship between Shyness and Guidance Needs among Adolescents 
.Journal of the Indian Academy of Applied Psychology, 34 (2), $317-322$.

- Zhang, Y. (2012). An Examination of Acculturative Stress Perceived Social

Support and Depression among Chinese International Students, Master of Science in Child and Family Studies, Syracuse University.

- Sabouripour, F. \& Roslan, S. B. (2015) . Resilience, Optimism and Social Support among International Students, Asian Social Science , 11 . 